\title{
ПЕРСПЕКТИВНЫЕ НАПРАВЛЕНИЯ ВНЕДРЕНИЯ БЛОКЧЕЙН-ТЕХНОЛОГИИ NFТ В РОССИЙСКУЮ ЭКОНОМИКУ
}

\author{
(c) 2021 Фомин Дмитрий Александрович \\ аспирант департамента «Экономическая теория» \\ Финансовый университет при Правительстве Российской Федерации, Россия, Москва \\ E-mail: fomin.lopukhin@gmail.com
}

За первый квартал 2021 года блокчейн-стартапы привлекли рекордный объем инвестиций. В частности, венчурные инвестиции получили проекты, работающие с технологией “невзаимозаменяемых токенов”. На данный момент технология нашла применение в сфере искусства, но ее потенциал значительно шире. Статья описывает, как устроена технология, называет перспективные сферы для ее внедрения и барьеры, препятствующие этому.

Ключевые слова: блокчейн, невзаимозаменяемые токены, криптовалюта, стартап, экономика, недвижимость.

Введение. Во время кризиса 2020-2021 годов, вызванного пандемией коронавируса, новый виток роста получил рынок криптовалют. Биткоин, первая и главная криптовалюта, в марте 2020 года дешевел до $\$ 3,8$ тыс. вслед за падением на фондовом рынке. За последующие 13 месяцев цена актива выросла примерно на $1600 \%$, установив в апреле 2021 года максимум на отметке в \$64,8 тыс. За тот же период капитализация всего крипторынка поднялась с $\$ 150$ млн. до \$2,5 трлн., показав роста почти на 2000\%.

Такая динамика вызвана в частности возросшим признанием криптовалют в финансовом секторе. Сначала в цифровые активы начали вкладывать капитал крупные институциональные инвесторы, в числе которых компания Илона Mаска Tesla [2]. Затем фондовые биржи стали добавлять новые инструменты на базе криптовалют: в феврале 2021 года Чикагская товарная биржа (CME) добавила фьючерсы на Ethereum, а затем ее подразделение CME Group запустило микрофьючерсы на Bitcoin. Одним из последних свой вклад в признание цифровых активов внес инвестиционный банк Goldman Sachs, в письме Global Marco Research назвав криптовалюты новым классом активов и отметив высокий спрос на них среди институциональных инверторов.

На фоне положительной динамики рынка цифровых активов инвестиционные и венчурные фонды стали активно инвестировать в криптостартапы, которые разрабатывают технологичные, инфраструктурные решения для криптоиндустрии и других отраслей. Так, согласно отчету аналитической компании СB Insights,

за первый квартал 2021 года крупные блокчейнстартапы привлекли \$2,6 млрд. [5]. Это больше, чем за весь 2020 год, когда совокупный объем инвестиций в блокчейн-индустрию составил $\$ 2,3$ млрд. Рост объема венчурных инвестиций в отрасль важен для экономики, так как венчурный капитал является катализатором новейших, “прорывных” технологий [1].

В частности, капитал был направлен в одну из самых быстро развивающихся сфер рынка цифровых активов, построенную на блокчейнтехнологии NFT. По данным аналитической компании Dapp Radar, объем криптотранзакций, связанных с NFT, в первом квартале 2021 года достиг \$1,5 млрд., рост к предыдущему кварталу составил более $2600 \%$ [6]. В данной статье будет рассмотрено текущее применение данной технологии, ее особенности и потенциал использования в других, не связанных с криптовалютой отраслях.

Как устроена технология NFT. NFT расшифровывается как Non-fungible Tokens, в переводе на русский - невзаимозаменяемые токены. Каждый NFT представляет собой отдельный, уникальный токен, выпущенный на блокчейне криптовалюты. Первые NFT были разработаны на базе биткоина, однако в дальнейшем технология развивалась преимущественно на базе Ethereum [3].

По своей задумке NFT-токен представляет собой цифровые права на физический или цифровой объект. Свое первое и на текущий момент основное применение данная технология нашла в сфере искусства. Пользователи выпускают 
NFT-токены на собственные картины, фотографии, музыкальные композиции, цифровые объекты и иные художественные работы, а затем продают эти токены на специальных платформaх. Купивший NFT становится полноправным владельцем оригинальной работы, может хранить ее как инвестицию и в коллекционных целях, а впоследствии - перепродать другим коллекционерам.

В конце 2017 года на фоне стремительного роста курса биткоина до предыдущего исторического максимума в $\$ 20$ тыс. в сфере NFT случился первый бум. Большой популярностью пользовались “криптокотики”. Это выпущенные на блокчейне Ethereum NFT-токены на цифровые, анимированные рисунки котят. Пользователи покупали “криптокотят” в коллекционных целях, впрочем, основной целью была перепродажа по более высокой цене. Стоимость “криптокотят" зависела от уникальности каждого цифрового рисунка и его оценки сообществом и могла достигать несколько тысяч долларов. Самый дорогой экземпляр был куплен в начале 2018 года за 600 Ethereum. На тот момент сумма сделки составляла около $\$ 600$ тыс.*

В начале 2018 года рынок криптовалют перешел в фазу долгосрочного снижения, вместе с тем и интерес к сфере NFT резко упал и оставался на низком уровне вплоть до конца 2020 года. Затем, на фоне стремительно роста капитализации рынка цифровых активов спрос на NFT вернулся в новых масштабах. Если ранее данной технологией интересовался небольшой круг лиц, то теперь собственные NFT-токены стали выпускать деятели сферы искусства, мировые звезды и известные компании, не имеющие прямого отношения к криптоиндустрии. В их числе журнал TIME, выпустивший NFT-токены на обложки своих изданий, Нью-Йоркская фондовая биржа, создавшая серию коллекционных NFT-токенов в память о первых публичных сделках, сеть ресторанов быстрого питания McDonald's и многие другие. В то же время интерес к сегменту NFT проявили организаторы мероприятий, среди которых Аукционный дом Christie's, организовавший серию аукционов NFT-токенов, и музей Эрмитаж, анонсировавший проведение в 2021 году первой в России выставки NFT-токенов ис- кусства. Такой охват показывает, что технология NFT “выросла” из забавы в технологический способ передачи прав на имущество. Разберемся, какими преимуществами обладает этот способ благодаря блокчейну.

В первую очередь блокчейн обеспечивает прозрачность. Несмотря на то, что с момента продажи самого дорогого “криптокотика” прошло более трех лет, сейчас любой пользователь может просмотреть транзакцию передачи NFT-токена, открыв запись с помощью обозревателя блокчейна ${ }^{* *}$. Можно узнать, кто купил токен и кто продал его, какие с ним были совершены операции после сделки, когда, кем и на какие суммы.

Вторая важная черта - достоверность информации. Блокчейн исключает вероятность пропажи или изменения данных о передаче токена. Все операции, которые когда-либо были или будут совершены с токеном, останутся действительными, пока будет работать сам блокчейн.

Отдельно стоить отметить защищённость данных. Пользователь хранит свои цифровые права в виде NFT на персональном криптокошельке. Надежнее всего для этих целей использовать холодные блокчейн-кошельки. Это своего рода флешка с возможностью установки пароля и отсутствием выхода в интернет. Использовать такое устройство можно только имея к нему непосредственный, физический доступ и зная кодовое слово. Также NFT можно хранить на криптокошельках, установленных на смартфон или в браузере на персональном компьютере. Отсутствие расходов на хранение информации также играет важную роль. Данные записываются в блокчейн, под их содержание не требуется выделять сервера.

Перспективные направления внедрения NFT. Перечисленные ранее характеристики блокчейна могут сделать технологию NFT высокоэффективным инструментом в различных сегментах экономики. Одно из самых перспективных направлений внедрения NFT - сфера недвижимости. Сейчас для регистрации жилья собственнику необходимо представить в Росреестр перечень документов. После этого недвижимость регистрируется в ЕГРН и выдается

\footnotetext{
* Ссылка на транзакцию передачи прав на «криптокотенка» https:/etherscan.io/tx/0x09bd9357d29bef46a68a6ffd c915304288d69ca089412a2edec0c8d370b3944b

** Обозреватели блокчейна - специальные веб-ресурсы, такие как etherscan.io, которые позволяют просматривать транзакции, записанные в блокчейне.
} 
паспорт собственника квартиры, который впоследствии потребуется для совершения с ней других сделок.

Технология NFT может быть внедрена на этапе регистрации. В таком случае помимо паспорта собственник будет получать NFT-токен, представляющий собой цифровые права на недвижимость. Этот токен будет содержать ключевую информацию о недвижимости, такую как данные о ее владельце, ее параметры, изначальную стоимость и прочие характеристики. K последним можно отнести сведения о сдаче квартиры в аренду или ссылки на материалы, содержащие сведения о первоначальном или текущем состоянии жилья. Эти сведения можно дополнить в NFT-токен уже после его выпуска.*

Благодаря этому в случае последующей перепродажи недвижимости, ее будущий покупатель сможет проверить все данные о ней перед совершением сделки, что повысит прозрачность операции и устранит сомнения в достоверности сведений. Для этого достаточно будет перейти по ссылке, представленной собственником, в обозреватель блокчейна и изучить историю квартиры. Таким образом покупатель сможет убедиться, например, что токен был выпущен и выдан собственнику именно Росреестром и, соответственно, не является подделкой.

NFT-токен на собственность можно интегрировать на различных платформах, ориентированных на операции с недвижимостью. Собственник, выставляющий жилье на продажу или для сдачи в аренду, сможет указать в объявлении адрес своего NFT-токена в блокчейне. Так, токен будет выступать в качестве гаранта заявленных характеристик.

Использование технологии NFT также ускорит процесс оформления сделок по передаче недвижимости, так как снизит бюрократические издержки. Вдобавок при продаже собственности в транзакцию можно записать данные о контрагенте, который участвовал в сделке. Таким образом агентства недвижимости, риелторы, нотариусы и другие возможные участники сделки смогут зафиксировать свое участие в ней в блокчейне и после использовать данную запись для формирования прозрачной отчетности, статистики, в репутационных целях.

Наибольшую выгоду от внедрения цифровых прав в виде NFT-токена получит государ- ство. Контролирующие органы смогут в режиме реального времени контролировать сделки, совершаемые с недвижимостью, что будет полезно в первую очередь для целей налогообложения. Блокчейн позволяет включить в NFT-токен функцию, которая будет автоматически сообщать в налоговые органы о продаже квартиры или сдаче ее в аренду с указанием суммы операции и информации о контрагентах. Вдобавок, контрольные органы будут иметь возможность моментально отслеживать крупные или подозрительные сделки с недвижимостью. Для этих целей можно пометить в блокчейне кошельки подозрительных собственников и других участников рынка, и когда те будут совершать операции, система будет присылать оповещение.

Стоит подчеркнуть положительный потенциальный вклад внедрения NFT в формирование статистики. Чем больше прав на недвижимость будет оформлено с помощью NFT, тем прозрачнее будет становиться вся отрасль. Данные будут фиксироваться в блокчейне, благодаря чему можно будет оперативно собирать достоверную статистическую информацию о колебаниях рынка недвижимости: об изменениях спроса и предложения, цен, активности покупателей и продавцов и другие данные. Это в свою очередь приведет к повышению точности исследований рынка и прогнозных моделей.

Другим перспективным направлением внедрения NFT-технологий является автомобильная индустрия. Как и в случае с недвижимостью, права собственника на машину можно оформлять в цифровом виде, выпустив NFT-токен. В этом случае общество и государство получат те же выгоды, что и случае с недвижимостью: государство сможет отслеживать все операции в онлайн-режиме, потенциальные покупатели смогут проверять достоверную информацию об истории автомобиля, снизится степень бюрократии.

Но потенциал применения NFT в автомобильной отрасли на этом не ограничивается. Наибольшего эффекта можно добиться, если органы ГИБДД и страховые агентства получат полномочия пополнять информацию, занесенную в NFT. Это будет полезно для учета дорожнотранспортных происшествий, данных о прохождении обязательного тех.обслуживания и т.д. Уполномоченные лица будут вносить сведения,

* Данные, записанные в NFT, невозможно изменить. Но к ним можно добавить новые сведения, проведя дополнительную транзакцию. 
например, об аварии, случившейся с транспорTOM, в его NFT. Впоследствии, если этот автомобиль будет выставлен на продажу, потенциальный покупатель сможет получить всю важную информацию из блокчейна.

Препятствия внедрению NFT. Ключевой проблемой для внедрения технологии NFT в экономику является юридическая сторона вопроса. На данный момент нет страны, в которой данная технология введена в правовое поле. В связи с этим покупатели NFT приобретают цифровые права, не признанные государством, отчего рискуют обменять деньги на “фантик”.

Другой проблемой является отсутствие инфраструктуры [4]. Для передачи цифровых прав в виде NFT пользователю достаточно отправить токен со своего блокчейн-кошелька на кошелек покупателя. Это можно сделать собственноручно или разместив объявление о продаже NFT на специальной платформе. Когда стороны придут к соглашению, платформа оформит операцию, собственнику нужно будет только подтвердить ее в персональном блокчейн-кошельке.

На данный момент существует ряд специальных частных платформ для обмена NFT-токенами: Rarible, Opensea, Mintable, Foundation и другие. Преимущественно они используются для купли-продажи предметов искусства: пользователи посредством NFT реализуют цифровые произведения искусства или цифровые права на физические предметы искусства. Данная технология начинает применяться для продажи недвижимости, дома в виде NFT выставлены на продажу в США и Украине. Однако сделки с недвижимостью редкость и уместны только в частных случаях.

Чтобы внедрение NFT в экономику принесло пользу всей системе, необходимо государственное участие. Требуется разработка платформ, посредством которых государственные органы смогут выпускать NFT-токены и дополнять в них информацию. Помимо разработки законодательной базы, важно ввести единые стандарты на NFT-токены. В таком случае пользователи смогут размещать цифровые права, выпущенные государственными органами, на сторонних платформах без нужды подстраиваться под программное обеспечение каждой из них. Как итог, чем глубже механизм цифровых прав будет интегрирован в систему, тем больший возможен положительный эффект.

\section{Библиографический список}

1. Валеев Э.Р. Венчурный капитал как фактор модернизации экономики // Экономические науки. - 2011.No 12(85).- С. 94-96.

2. Фомин Д.А. Формирование децентрализованных финансовых институтов в качестве альтернативы кредитно-финансовым организациям // Экономические науки._-2021.- No 3 (196). - С. 33-37.

3. Dowling M. Fertile LAND: Pricing non-fungible tokens // Finance Research Letters. [Элек-тронный ресурс].2021.- Режим доступа: https://doi.org/10.1016/j.frl.2021.102096 (дата обращения 12.05.2021).

4. Ullah F., Samad M.E., Thaheem M.J., Al-Turjman F. Barriers to the digitalisation and innovation of Australian Smart Real Estate: A managerial perspective on the technology non-adoption // Environmental Technology \& Innovation. [Электронный ресурс].- 2021.- Режим доступа: https://doi.org/10.1016/j.eti.2021.101527 (дата обращения 15.05.2021).

5. Отчет CB Insights: Venture Capital Funding Headline Report Q1 2021.- [Электронный ресурс].- Режим доступа: https://www.cbinsights.com/reports/CB-Insights_MoneyTree-Q1-2021-Headline.pdf (дата обращения 10.05.2021).

6. Отчет Dapp Industry Report: Q1 2021 [Электронный ресурс].- Режим доступа: https://static.coindesk.com/wpcontent/uploads/2021/04/Dapp-Industry-Report_Q1-2021.pdf (дата обращения 11.05.2021). 